\title{
Aporte de la imagenología en las enfermedades respiratorias
}

En las $27^{a s}$ Jornadas de Otoño, nuestra Sociedad organizó un simposio sobre el aporte de la imagenología en las enfermedades respiratorias, tema que con el desarrollo de las técnicas tradicionales y de nuevos procedimientos, se ha transformado en herramienta fundamental en el diagnostico clínico. Los procedimientos modernos han llegado a un nivel tal, que incluso en muchas ocasiones permiten obviar procedimientos invasivos y estudios histológicos, ya que nos entregan imágenes de 200 a 300 um con una correlación muy estrecha de lo que está ocurriendo en el pulmón.

La radiografía convencional en dos planos ocupa un lugar tan cotidiano como el estetoscopio en la práctica clínica neumológica habitual, disponible hasta en los más distantes centros de atención, la cual, con una sensibilidad más que probada, permite día a día resolver problemas diagnósticos cotidianos o sospechar patologías que requieren mayor estudio. Este elemento imagenológico también se ha desarrollado con la digitalización, entregándonos imágenes de mayor resolución, mayor amplitud de grises y, además, capaces de archivarse, transmitirse y modificarse. Esto abre la puerta a lo que se ha denominado "telemedicina", lo que básicamente significa conectividad. Así, por ejemplo, podemos trasmitir a distancia imágenes para interconsultas, discusión de casos e incluso adjuntarlas a una ficha clínica electrónica, elementos que pueden ser de gran utilidad para médicos no especialistas. Esta posibilidad está disponible en muchos lugares, sólo se necesita de la decisión política que permitiría implementarla en todo Chile.

La tomografía computada (TC) ha seguido un desarrollo vertiginoso, contando hoy con el llamado "TC multicorte", que consiste en un recorrido helicoidal a través del tórax por un amplio haz de rayos $X$ que es recibido por varias corridas de detectores -actualmente hasta 64 corridas(llamados también “canales"). Esto significa que en vez de obtener cortes, se obtiene un volumen de información, con el cual se pueden realizar cortes en cualquier dirección e incluso imágenes tridimensionales, eligiendo la porción de información que nos interesa. El resultado de esta técnica nos entrega básicamente tres ventajas: imágenes de mucha mayor resolución cercanas a los $200 \mu$ m (TC de alta resolución); cortes en diferentes planos, lo que nos permite una correlación más estrecha con estructuras vecinas (reconstrucción multiplanar); y, finalmente, muchísima mayor velocidad de adquisición (aproximadamente 10 segundos o menos), lo que ha abierto el camino a la angio TC.

La tomografía computada de alta resolución nos permite observar imágenes con niveles cercanos a los cortes histológicos, con una precisión nunca antes sospechada. La mirada del radiólogo experto en conjunto con los antecedentes clínicos, nos permite en ocasiones hacer diagnósticos muy precisos, que evitan someter a los pacientes a procedimientos invasivos, como ocurre en el caso de la fibrosis pulmonar idiopática. Es frecuente escuchar a patólogos correlacionar sus hallazgos histológicos con la imagenología, modificando la interpretación de sus biopsias, porque -a diferencia del trozo pequeño que puede ser estudiado en una biopsia- la tomografía nos ofrece una mirada panorámica de lo que ocurre en todo el tórax.

Las proyecciones multiplanares permiten sobre todo en patología neoplásica y mediastínica una aproximación más estrecha en cuanto a la relación de estructuras vecinas en la etapificación de las neoplasias.

La angio TC, permite obviar procedimientos invasivos para el estudio de patología vascular. Por ejemplo su aporte en el tromboembolismo pulmonar permite un diagnóstico en pocos segundos, sin riesgos y además brindando más información al demostrar la patología consecutiva a la obstrucción 
vascular o también al demostrar patología alternativa que puede simular un tromboembolismo en el cintigrama de ventilación-perfusión.

Vivimos hoy una revolución intervencionista en imagenología, de perspectivas inimaginables. Estos procedimientos antes utilizados en el diagnóstico de lesiones vasculares -que hoy han sido reemplazados por la angio $T C$ - han evolucionado a procedimientos terapéuticos, como recanalizaciones de obstrucciones con dilataciones y stents, colocación de elementos intravasculares para obstruir malformaciones arteriovenosas o vasos dañados en pulmones destruidos. Así, el futuro se ve promisorio para el tratamiento de afecciones antes quirúrgicas, muchas veces mutilantes, como por ejemplo segmentectomías, lobectomías e incluso a veces neumonectomías, en pulmones dañados con hemoptisis agudas.

La ecotomografía, si bien no es un procedimiento de amplio uso en patología torácica, ha demostrado gran utilidad en enfermedades de la pleura, permitiendo de forma simple y rápida el estudio de derrames, efectuar marcaciones o servir de guía directa en punciones. La utilización de transductores endoscópicos resulta útil ocasionalmente para estudio de ganglios mediastínicos peritraqueales, e incluso ayudando en punciones de éstos.

Finalmente, debemos mencionar el gran aporte de la PET-CT, es decir, la tomografía por emisión de positrones (PET) combinada con la tomografía computada $(C T)$, que está revolucionando la imagenología diagnóstica y la etapificación de la enfermedad neoplásica del tórax. Fundamentalmente implica agregarle color a las imágenes tumorales activas, permitiendo así una demostración más precisa de las áreas comprometidas y adicionalmente poder detectar compromisos metastásicos a distancia. Es la combinación de la tomografía computada con la tomografía por emisión de positrones lo que potencia ambos procedimientos.

Las jornadas de Mantagua nos adentraron en este mundo nuevo, amplio, fascinante y dinámico, reafirmando nuestros conocimientos junto con darnos a conocer nuevas aplicaciones y formas de ver e interpretar este enorme cúmulo de información que aporta la nueva imagenología. De esta forma quisiera recalcar algunos conceptos y conclusiones:

$1^{\circ}$ La imagenología moderna tiene una alta sensibilidad en el diagnóstico y nos entrega muchísima información.

$2^{\circ}$ El pulmón tiene una forma muy limitada de reaccionar a los agentes etiopatogénicos, lo que implica una baja especificidad de las alteraciones histológicas y radiológicas.

$3^{\circ}$ Estos dos hechos nos dejan tres desafios al enfrentar problemas respiratorios:

- Prepararnos científicamente, para comprender los hechos clínicos, histológicos y radiológicos;

- Estudiar la información de forma sistemática; e

- Interactuar con los colegas involucrados, esto es el clínico, el radiólogo y el patólogo deben entrar en comunión.

Este es el nuevo enfrentamiento diagnóstico, este es el nuevo desafío al que nos enfrentamos en la práctica médica respiratoria. Usemos las herramientas que la imagenología moderna pone a nuestra disposición.

\section{Bibliografía}

1.- MULLER N L, FRASER R S, COLMAN N C. Radiologic diagnosis of diseases of the chest. Philadelphia. PA. USA. Saunders. 2001.

2.- VANSTEENKISTE J F. Imaging in lung cancer: PET scan. Eur Respir J 2002; 35: 49s-60s.

3.- WERNECKE K. Ultrasound study of the pleura. Eur Radiol 2000; 10: 1515-23. 